\title{
DA RELAÇÃO PENSAMENTO E LINGUAGEM AO ESTUDO INTERDISCIPLINAR DA MENTE
}

\author{
Onici Claro Flôres ${ }^{1}$ \\ Rosângela Gabriel ${ }^{2}$
}

Resumo: Neste ensaio, retoma-se a discussão sobre a relação pensamento e linguagem, ampliando-se o escopo da abordagem, e substitui-se o termo pensamento por cognição; acrescentam-se ao debate o contexto cultural, como fator essencial, e não apenas como pano de fundo, e os estudos do cérebro, como sustentação de algumas hipóteses teóricas atualmente veiculadas. Ademais, são introduzidos os conceitos de metalinguagem e de atividade metalinguística, relacionando-os a pesquisas sobre afasia. Argumenta-se sobre a importância da cultura e da vida em sociedade para a cognição, além de se dar destaque aos estudos do cérebro, historicamente rechaçados por motivos religiosos ou éticos. Em pauta estão as bases biológicas e, possivelmente, também culturais de uma possivel diferença no estado inicial do processo de construção do conbecimento, cuja discussão continua, na atualidade, enfocando cognição/linguagem/ contexto cultural/cérebro (corpo) como uma relação essencial às pesquisas na área das Ciências Cognitivas.

Palavras-chave: Cognição. Linguagem. Metalinguagem. Atividade metalinguistica. Afasia.

\section{INTRODUÇÃO}

Embora a relação entre cognição e linguagem tenha sido bastante investigada ao longo do tempo, a inclusão do contexto cultural não era sequer cogitada, pois, de modo geral, os estudiosos assumiam uma visão asséptica do conhecimento. O normal e o patológico costumavam ser dissociados, desconsiderando-se que a fronteira não era tão nítida quanto parecia. Porém, a despeito de a tendência fisicalista ser majoritária no tratamento de doenças que afetassem a linguagem durante décadas, o cérebro de pessoas vivas era inacessível até bem pouco tempo atrás. Assim, apenas a partir dos anos 90, quando as neurociências alcançaram maturidade científica e desenvolveram aparato teórico-metodológico adequado para analisar o funcionamento de cérebros intactos, foi

\footnotetext{
${ }^{1}$ Doutora em Letras. Professora do Departamento de Letras e do Mestrado em Letras - Leitura e Cognição, Universidade de Santa Cruz do Sul (UNISC). Email: oflores@unisc.br.

${ }^{2}$ Doutora em Letras. Professora do Departamento de Letras e do Mestrado em Letras - Leitura e Cognição, Universidade de Santa Cruz do Sul (UNISC). Email: rgabriel@unisc.br.
} 
possível incluir os estudos de cérebros ativos nas investigações realizadas. Desse modo, ainda que este estudo não tenha natureza neurocientífica, ele destaca a necessidade de considerar esse tipo de abordagem como parte do estudo interdisciplinar da mente. De fato, não há como evitá-lo, já que as investigações realizadas na área médica analisam um dado cérebro, corporificado, parte de uma dada pessoa, que integra determinado grupo sociocultural e fala, pensa e age, enquanto um todo. Assim, a necessidade de considerar esses fatores tornou-se mais evidente na fase atual dos estudos sobre cognição, até porque "o funcionalismo teve como mérito solapar a crença ingênua num puro e simples isomorfismo entre computadores e cérebros [...]" (TEIXEIRA, 2004, p. 27). Em suma, hoje já se tem evidências suficientes de que o cérebro humano não funciona do mesmo modo num tubo de ensaio e num corpo em atividade (embodied cognition).

A observação deve-se ao fato de o conceito de cognição associarse ao estudo da percepção e da atividade motora, e não exclusivamente ao pensamento ou às atividades mentais superiores, como se tendia a considerar. A abordagem de hoje é mais ampla, pois a cognição abarca o estudo da sensação física (perceptual) e do pensamento, bem como sua inter-relação, não se referindo com exclusividade ao pensamento, mas à linguagem, à percepção, às emoções, à atenção, à memória e assim por diante.

Até o momento, entretanto, apesar de serem referidos com assiduidade, os processos mentais superiores só são acessíveis para descrição e explicação através de especulação filosófica, enquanto os processos perceptuais e motores apresentam um vasto campo objetivo e material de estudos científicos já realizados. Essa circunstância particular faz com que as explicações científicas a respeito da mente humana, de modo geral, pautem-se por suas origens históricas, epistemológicas e ideológicas, aliadas a um modesto número de achados propriamente científicos, os quais acabam sendo complementados pelos pressupostos teóricos assumidos pelos pesquisadores (DUPUY, 1996).

Em vista disso, discutir o que seja cognição é um tema complexo, de vez que envolve questões fundamentais do conhecimento humano e 
comporta controvérsias conceituais de base. Do ponto de vista histórico, o conceito de cognição relaciona-se ao dualismo cartesiano - cogito ergo sum - princípio fundamental do método científico (FREITAS, 1994), tendo, além disso, passado a integrar a base conceitual das ciências da computação, mais recentemente. Esse duplo vínculo caracteriza o movimento cognitivista original como preconizador de uma visão formalista, fisicalista e mecanicista dos processos mentais e da razão humana. Em vista disso, quando alguém aborda o tema cognição, o ouvinte/leitor entende que se trata de uma investigação que busca uma resposta científica, digamos de tipo simbolista, ao problema filosófico da relação entre a alma e o corpo (DUPUY, 1996).

Há, porém, posições discordantes em relação ao conceito de cognição nos moldes referidos acima, quando o ponto de partida é o estudo da linguagem, por exemplo. $\mathrm{Na}$ verdade, para concordar com tal posição, seria preciso postular uma concepção de linguagem mecanicista e instrumental. Em vista disso, a opção por conceber a linguagem como um processo intersubjetivo situado, social e culturalmente, representa uma oposição frontal aos preceitos teóricos das pesquisas cognitivistas mais tradicionais, pois a linguagem deixa de ser vista apenas como a manifestação de uma estrutura formal da língua, do pensamento ou de processos cognitivos mais primários, passando a ser considerada como uma atividade estruturada e estruturante desses processos (percepção, língua, pensamento etc.).

Assim, para além de suas categorias estruturais, para além de um sistema determinístico, a linguagem enquanto atividade constitutiva expande as fronteiras do linguístico, redefinindo-o. Nessa perspectiva, linguagem e cognição são vistas como interdependentes, e a língua não mais é concebida como um sistema baseado em princípios invariáveis, sejam eles estruturais, sintáticos, ou, ainda, referentes denotativos da realidade, moldados de antemão na mente dos indivíduos.

A posição opositora aos estudos cognitivistas é postulada, dentre outros teóricos, por Morato $(2001,2004)$ que, referindo-se aos estudos neurocognitivos, afirma ser tradicional na área aceitar como indiscutível a existência de uma divisão entre o linguístico e o cognitivo. De acordo 
com a autora, as afasias são consideradas problema linguístico, mais precisamente, metalinguístico, e as neurodegenerescências (por exemplo, doença de Alzheimer) problemas cognitivos, conceituais, psicológicos. Em suma, estes últimos não são considerados problemas linguísticos. A bipartição referida evidencia a divisão existente entre os estudos de cognição e de linguagem, deixando claro que a cognição ainda tem precedência sobre a linguagem, na área médica, mesmo hoje. Consequentemente, não é possível persistir ignorando que a dissociação entre cognição e linguagem é histórica, tendo origem em uma divisão disciplinar.

Mas, afinal, o que é linguagem? Profissionais de várias áreas - não propriamente leigos - entendem a linguagem como um subproduto do pensamento. Outros pensam nela em termos estéticos, retóricos, e assim por diante. As possibilidades são muitas. E elas, de fato, existem. Contudo linguagem é também cognição. Resta esclarecer, então, a essencialidade da linguagem em termos cognitivos, uma vez que ela não é apenas um epifenômeno, como o concebeu Piaget (1974, 1985), por exemplo.

Ressalta-se de antemão que, hoje em dia, já há modelos teóricos que buscam dar conta da inter-relação entre linguagem/cognição/cultura/(corpo)cérebro, mas o fato é que não existem ainda modelos que fundamentem, em um mesmo mecanismo explicativo, todos os conceitos/mecanismos envolvidos, apesar de bom número de propostas ter sido veiculado. Para exemplificar, podem-se citar pesquisadores como Foley (1997), Fauconnier e Turner (2002), Fauconnier (1994), assim como Tomasello (2003), Sinha (2005), Miranda e Salomão (2009) e outros.

O panorama está se alterando, como visto, mas isso não faz desaparecer de imediato as divergências. Assim, tem-se a acrescentar que linguistas se dedicarem ao estudo da linguagem, psicólogos cognitivos e neurologistas à cognição e aos estudos do cérebro, e antropólogos às questões culturais não parece ser um paralelismo qualquer que possa ser considerado de maneira ligeira e superficial. A aproximação teórica é problemática, dando ensejo a embates diversos, sendo que as tentativas 
de estabelecimento de uma unidade de estudo encontram barreiras de toda sorte. Contudo, a ciência dos contrários é una, já o afirmava Aristóteles, apesar, é claro, de a continuidade dos estágios sucessivos de um ao outro polo - não anular a diferença das extremidades. Por isso mesmo não é produtivo identificar os conceitos, nem mesmo os de cognição e linguagem, reduzindo um ao outro. É preciso relacioná-los.

Marková (2006), por exemplo, propõe uma abordagem teórica que visa a superar esse tipo de impasse, sugerindo a investigação e análise do que ela chama de pensamento opositor. De acordo com ela, as antinomias estão presentes na maioria dos estudos científicos sendo, pois, aconselhável considerá-las como constitutivas da mente humana a mente dialógica. Seu enfoque é favorável à coexistência das oposições em um todo constitutivo, interdependente e unificado. A constituição desse todo implicaria a integração de conceitos tidos como opostos, ou, pelo menos, como não redutíveis um ao outro. Parece, então, que a expressão "polaridade dinâmica", utilizada por Canguilhem (1995), pode ser relacionada teoricamente à proposta de Marková e reforça a necessidade de relacionar cognição, linguagem e cérebro, bem como contexto cultural, propiciando estudos menos dissociados e estanques.

Se considerado o pensamento antinômico, a primeira decorrência seria que a relação cognição/linguagem devesse envolver reciprocidade, podendo inclusive admitir relações assimétricas, porém nunca dissociadas. Ambas constituiriam as forças de equilíbrio da atividade psíquica, ao mesmo tempo, em proporções diferentes, possivelmente, mas sempre em relação.

\section{DE QUE FORMA A LINGUAGEM MOBILIZA O CÉREBRO?}

Um autor que discutiu extensamente a questão levantada no título desta seção, ou seja, de como o uso da linguagem mobiliza o cérebro a fim de processar, compreender e produzir linguagem e pensamento foi Luria (1986). Para ele, a interação humana é a propulsora dos processos de construção da significação, sendo que a linguagem, por integrar a estrutura dos processos cognitivos, encarrega-se de regular e mediar toda a 
atividade psíquica. Segundo ele, regulação e mediação se expressam através da emergência de dois tipos de operações. As primeiras, chamadas de epilinguísticas - hesitações, autocorreções, reelaborações, rasuras (na escrita), pausas longas, repetições, antecipações e lapsos estão presentes no processo de aquisição da linguagem (KARMILOFFSMITH, 1979, 1986; DE LEMOS, 1982), sendo, também, usuais no processo de reconstrução da linguagem pelo sujeito afásico (COUDRY, 1988).

As operações do segundo tipo, consideradas propriamente metalinguísticas, não são espontâneas, dependendo do monitoramento ativo do falante sobre o dizer e o querer dizer. De acordo com Luria, a natureza dialética da interlocução possibilita a manifestação das coordenadas linguísticas e psíquicas constitutivas do funcionamento da linguagem, porque ela [linguagem] é uma atividade que se estrutura de forma gradual, através desses dois tipos de operações, até porque a interlocução naturalmente as elicita, dada a sua natureza dialógica. Em decorrência, à noção de linguagem como ação, atividade, ou operação, ajusta-se como uma luva uma concepção dinâmica do funcionamento do cérebro. E é esse caráter de dinamicidade que, afirma Luria, constitui-se no eixo que possibilita as relações entre linguagem e cognição e sua interrelação.

Básico para discutir a perspectiva teórica em questão é o modo de ver a linguagem, pois se a organização do mundo e das relações intersubjetivas processa-se por meio dela, então a linguagem deve possuir mecanismos inter e intrapsíquicos que se ocupem do seu arranjo, quando em funcionamento. De acordo com essa concepção, são os processos epilinguísticos e metalinguísticos que mostram quando o sujeito se monitora ou se autorregula, fazendo autocorreções e reinterpretações da fala do outro; ou quando hesita, subentende, retoma suas próprias palavras, comete atos falhos, pressupõe e assim por diante. Tais comportamentos não podem ser estruturados segundo a lógica matemática, porque nesse caso se perderiam as coordenadas dêiticas da situação interativa, as pressuposições de conhecimento, as imagens recíprocas dos interlocutores a respeito de si e do outro, as inferências e tudo mais que não seja estritamente lógico. 
Em suma, os processos epilinguísticos regulam o fluxo da linguagem e vão ficando mais conscientes, portanto se convertendo aos poucos em processos metalinguísticos, manifestando-se num contínuo, desde uma operação inconsciente até uma atividade reflexiva e deliberada em função de algum objetivo preciso. É claro que o processo comentado não se reduz à racionalidade: há o fator emocional envolvido. Mas, a emoção integra a cognição em seu todo - cognição/emoção. Enfatiza-se, além disso, que as operações de que se fala são dois tipos de atividades e não apenas um, ou seja, não é possível reduzir a atividade epilinguística à metalinguística nem vice-versa. Luria destaca a essencialidade dessas operações. Em sua ótica, o domínio dos recursos expressivos e o seu manejo não são exclusivamente uma questão cognitiva, já que ambos se relacionam à propriedade dialógica fundamental da linguagem: a propriedade da reversibilidade dos papéis na interlocução - o $e$, o $t u$, e a propriedade eventual de ambos serem tratados como ela/ ele, quando uma dada pessoa passa à condição de não sujeito, sendo referida como ela/ ele, em sua presença, como se fosse um objeto inerme deixado 'à beira do caminho' pelos demais, fora da conversa e da vida cotidiana (COUDRY, 1988).

De Lemos, por exemplo, reconhece, com relação à aquisição da linguagem, que "o projeto teórico [...] sociointeracionista não foi bem sucedido, na medida em que não conseguiu demonstrar como as propriedades estruturais e as categorias da linguagem e do raciocínio podem ser derivadas de processos interativos" (DE LEMOS, 1998, p.152). A autora sugere, entretanto, uma alternativa, que é a consideração do "funcionamento mesmo da linguagem numa língua particular, ao qual tanto as crianças quanto o adulto estão submetidos, [pois é por meio desse funcionamento] que estes [adultos e crianças] mantêm uma relação transformada com o mundo" (DE LEMOS, 1998, p. 169-170). Em outras palavras, a autora ressalta as operações de reorganização e ressignificação no interior do próprio enunciado, dando ênfase aos processos metafóricos e metonímicos, como mecanismos desencadeadores de mudança. 
Em suma, os autores citados neste estudo concordam quanto à possibilidade de tratar a relação cognição/linguagem como uma unidade operacional, fundamentando-se na perspectiva do interacionismo, se o ponto de partida for o contexto enunciativo, ou contexto de uso da linguagem.

\section{O QUE SE CONSIDERA COMO METALINGUAGEM: METAPROCESSOS E EPIPROCESSOS}

Para caracterizar o que são e como ocorrem os processos epilinguísticos e metalinguísticos, é essencial conceituar metalinguagem, pois é essa propriedade da linguagem natural que possibilita a autorregulação, ou seja, a emergência dos dois processos considerados fundamentais para a unidade operacional cognição/linguagem. Assim, a seguir discute-se o conceito de metalinguagem com algum detalhamento.

Com base nos estudos das funções da linguagem de Jakobson $(1963,1974)$, existe certo consenso entre os linguistas, pelo menos entre os não chomskianos, quanto ao que seja metalinguagem. Porém, abordar a questão da metalinguagem é complicado, porque não se trata apenas de usar metalinguisticamente a língua portuguesa para referir-se à própria língua portuguesa, uma vez que, de fato, a metalinguagem é requerida também por filósofos, linguistas e outros estudiosos para falar tanto de línguas particulares, como da língua, em sentido amplo.

Rey-Debove (1978) afirma que usualmente ninguém contesta que a linguagem possua uma função metalinguística. O problema, segundo a autora, é que a metalinguagem também é uma língua usada para falar a respeito de outra língua. Nesses casos, quando se usa o português como metalinguagem para falar do francês, do inglês etc. é necessário recorrer a um conjunto de termos e conceitos técnicos. Da mesma forma agem físicos, químicos, lógicos, que inventam uma linguagem para usá-la como metalinguagem. Ou por outra, o nome autonímico, isto é, a palavra usada no fio do discurso, não requer descrição, diferentemente da expressão metalinguística, que o exige. Há que distinguir, portanto, palavras para 
falar da linguagem comum e palavras para falar dos vários campos do conhecimento. Então, quando se trata de discutir metalinguagem, é preciso explicitar a especificidade da metalinguagem enquanto linguagem. A autora ressalta, ainda, que: "O discurso metalinguístico, ao utilizar não importa que signo para dele falar, abre uma grande brecha nos sistemas das línguas, desde que qualquer fato discursivo pode aí se integrar". 3

Do exposto, depreende-se não ser nada simples definir metalinguagem. Além do mais, não se pode reduzir o conceito de metalinguagem à função metalinguística. De outra parte, discutir atividade metalinguística em relação à aquisição de uma língua não é o mesmo que discutir o conceito de modo lato. Em termos de aquisição, o pré-requisito é que o processo seja conscientemente conduzido e, por isso, sua emergência pressupõe que o sujeito seja capaz de reflexão e de monitoramento sobre a produção e a compreensão linguísticas de sua primeira língua. Por exemplo, ter noção do que seja palavra, letra, sílaba, fonema, etc.

Vários estudiosos dedicaram-se a esses estudos. Por exemplo, Karmiloff-Smith (1983) assegurou que as atividades metalinguísticas são um componente essencial da aquisição e do desenvolvimento linguístico, funcionando em todos os níveis, não se constituindo, pois, em epifenômeno de surgimento tardio, já que sua emergência se manifesta por volta dos cinco ou seis anos e ambos os tipos de atividade coexistem ao longo da vida. Os resultados das investigações dessa autora levaramna a diferenciar metaprocessos inconscientes de metaprocessos conscientes, podendo, os últimos serem verbalizados. Em 1986, Karmiloff-Smith publicou outro trabalho, propondo etapas de desenvolvimento da consciência metalinguística durante o processo de aquisição de linguagem (KARMILOFF-SMITH, 1986).

\footnotetext{
${ }^{3}$ No texto original: "Le discours métalinguistique, en utilisant n’importe quel signe pour en parler, ouvre une large brèche dans les systèmes des langues, puisque tout fait de discours est susceptible de s'y intégrer" (REY-DEBOVE, 1978, p.4).
} 
Fundamentando-se nos resultados desse estudo, a autora estabeleceu quatro níveis de representação do conhecimento:

a) o nivel implícito (N1), em que o conhecimento não é representado internamente de modo explícito;

b) o nivel de explicitação primária (NE-1), em que o conhecimento implícito é redescrito internamente, ou seja, sua estrutura interna é analisada com base no código original;

c) o nível de explicitação secundária (NE-2), em que o conhecido representado em NE-1 é outra vez descrito, sendo sua estrutura interna reanalisada com base nos diferentes códigos particulares que já integravam NE-1; e

d) o nivel de explicitação terciária (NE-3), em que o conhecimento representado em NE-2 é descrito pela terceira vez, dessa feita a partir de um intercódigo universal, dando origem a uma representação abstrata.

De acordo com a autora, apenas as representações resultantes das redescrições baseadas em códigos externos à representação original seriam acessíveis à consciência.

Essa divisão quaternária dos níveis de representação do conhecimento sustenta um modelo de aquisição da linguagem. De acordo com Karmiloff-Smith, nos dois primeiros níveis a linguagem é processada externamente. Assim, durante a fase inicial, a criança simplesmente registra aquilo que ouve, coletando, sobretudo, estímulos externos. Nessa fase, forma e conteúdo linguístico mantêm uma relação biunívoca, sendo o processo amplamente influenciado pelos julgamentos de aceitabilidade derivados das situações de interlocução vivenciadas pela criança. Os estímulos recebidos, na verdade, constituem um componente espontâneo e natural de sua inserção social e estão presentes no processo de interação. Ao final desse processo, a criança supostamente teria amealhado um conjunto de dados 'linguístico-situacionais' muito próximos daquele do adulto.

Em decorrência da aceitação e boa receptividade dos ouvintes, a criança vai acumulando, aleatoriamente, um grande volume de dados que lhe permitem passar para a etapa de sistematização. Nessa etapa, ela 
reorganiza os dados recolhidos à sua maneira, idiossincraticamente. A reorganização envolve tudo aquilo que ela conseguiu registrar na etapa anterior - a fase da coleta. Para sistematizar esses dados, a criança opera através de metaprocessos inconscientes, isto é, nos termos de Luria (1986), através de operações epilinguísticas.

Ao alcançar esse patamar, diz a autora, a criança desvia o foco da atenção do estímulo externo e se concentra na representação interna, a fim de analisar o conhecimento antes representado de modo superficial. No processo de explicitação primária do conhecimento implícito, a criança compara formas linguísticas entre si, o que favorece a organização do conjunto de dados acumulado. A sistematização acontece via redescrição do conhecimento, implicando focalizar a atenção na sua organização interna. No decorrer desse processo, o desempenho da criança costuma surpreender os adultos, pois se distancia da fala meramente imitativa, apresentando certas peculiaridades. Pais e professores, às vezes, comentam que a criança regrediu, pois passou a "errar" em situações em que não errava, ou seja, em situações em que anteriormente apenas reproduzia a produção do adulto. Exemplos sintomáticos dessa busca de sistematização em andamento são fenômenos como os de hiper-regularização, autocorreção e reparos.

A consolidação e estabilização do sistema construído conduzem a terceira e última etapa da aquisição da linguagem, na qual a criança estabelece vínculos mais estáveis entre estímulos externos, reanálise e representações internas. Desaparecem, nessa fase, as marcas peculiares e as autocorreções características da segunda etapa. Adicionalmente, e na proporção em que disponha de outros sistemas já estabilizados, é possível para a criança retomar o conhecimento já explicitado na fase anterior. A partir de então, ela reestrutura os subsistemas linguísticos, através de uma nova descrição em que utiliza códigos diferentes daquele da primeira análise. Esses códigos vão sendo aprimorados depois de cumpridas as demais etapas do processo.

Kolinsky (1986), corroborando as conclusões de Karmillof-Smith, também destaca ser necessário diferenciar dois tipos de habilidades. O primeiro traduzido na manifestação espontânea, e o segundo baseado no 
conhecimento representado, podendo ser a habilidade adquirida intencionalmente aplicada. Mais do que diferença de grau, o que existe, segundo Kolinsky, é uma diferença de natureza entre as atividades desenvolvidas em cada uma das circunstâncias. Esse argumento é decisivo, pois funciona como um divisor de águas entre processos epilinguísticos e processos metalinguísticos.

Quanto a essa distinção, vale acrescentar um comentário de Canguilhem:

No caso da linguagem, podem distinguir-se dois momentos na elaboração de uma proposição intencional e abstratamente significativa: um momento subjetivo em que as noções vêm à mente, de modo automático e um momento objetivo em que são intencionalmente dispostas [...]. (1995, p. 250).

Assim, em aquisição da linguagem, o termo 'epilinguístico' ficou reservado para indicar o comportamento metalinguístico cujo caráter inconsciente pareça estar suficientemente caracterizado. Portanto, usa-se aqui o termo 'metaprocessos' para indicar atividades metalinguísticas propriamente ditas, e 'epiprocessos' para indicar as atividades metalinguísticas de caráter não consciente.

As atividades ou processos epilinguísticos voltam-se, como visto, para a linguagem, porém a direção desse tipo de reflexão tem por objeto o uso dos recursos expressivos em função das atividades linguísticas em que "linguagem-situação" constitui um todo indissociável. Por sua vez, a atividade metalinguística, como uma reflexão analítica sobre os recursos expressivos que levam à construção de noções com as quais se torna possível a categorização de tais recursos, concentra-se nos próprios recursos. Portanto, para que tenha algum significado, já que o processo é escrutinador, lento e deliberado, é indispensável que as atividades epilinguísticas o tenham precedido, havendo, em vista disso, intercâmbio contínuo entre atividades epilinguísticas e metalinguísticas. Ou, em outros termos, uma coisa leva à outra. 


\section{COMO SE PROCESSAM AS OPERAÇÕES METALINGUÍSTICAS E EPILINGUÍSTICAS?}

As dúvidas e a busca de explicações a respeito do que está sendo dito, ouvido ou lido podem se manifestar através de pelo menos dois tipos de comportamentos verbais distintos, irredutíveis um ao outro:

a) aqueles nos quais o sujeito atenta para a linguagem, sua ou do outro, e faz reparos ou autorreparos espontâneos, sem tentar explicar porque fez o que fez. Quando assim age, o sujeito está exprimindo sua autopercepção, pois emite um julgamento sobre as expressões linguísticas utilizadas; porém, ao fazê-lo, não recorre à metalinguagem para corrigi-las, julgá-las ou avaliá-las. Nessas circunstâncias, sua avaliação embasa-se em algo externo à linguagem. No caso a seguir, a criança repete a opinião da mãe sobre a fala da avó, com quem conversa.

A: Vó, não é "tauba" é tábua, tu tá falando errado.

B: Ué, eu sempre falei assim e ninguém me corrigiu.

A: É, mas a mãe disse que tu fala errado;

b) aqueles nos quais o sujeito, além de focalizar a linguagem, fornece uma explicação ou faz um julgamento pessoal, cuja base é uma teoria, e, em vista disso, faz uso da metalinguagem. Veja-se o exemplo:
A: Mãe, olha ali! Garagem tá escrito errado.
$\mathrm{B}:$ Ab é? O que está errado?
A: Tá faltando um erre. Tá escrito gaagem.

Em termos de aquisição da linguagem, pode-se dizer que as operações epilinguísticas são frequentes, sobretudo, quando a criança ingressa na escola e começa a alfabetizar-se, isto é, quando tem contato com o ensino de leitura e de escrita de modo sistemático. Gombert (1992) reserva o termo 'epilinguístico' para indicar os comportamentos verbais de tipo (I), que se assemelham a comportamentos metalinguísticos, não sendo, contudo, controlados pelo sujeito que os 
formulou de modo consciente e proposital, em termos técnicocientíficos. Já o comportamento verbal de tipo (II) é considerado uma atividade 'metalinguística' típica.

\section{METALINGUAGEM E CONTEXTOS INTERATIVOS}

Como já comentado, a atividade metalinguística manifesta-se, em geral, via pergunta. Por exemplo, numa conversa entre mãe e filho, se a criança não entender uma palavra, simplesmente, perguntará o que ela significa, interrompendo a fala da mãe.

Mãe: Pedrinho, se gritasses menos, pouparias a tua garganta.

Pedrinho: Mãe, o que é pouparia'?

Como pode ser visto, o garoto não prosseguiu a conversa, ignorando o que fora dito. Ele concentrou-se na forma verbal 'pouparia' e fez a pergunta em busca de esclarecimento. Sabe-se lá se ele entendeu ou se considerou a reclamação da mãe!

A situação modifica-se, porém, caso a pergunta seja feita num outro ambiente social, digamos, na escola. Apesar de operar da mesma forma, isto é, envolver o proferimento de uma pergunta, nesse caso dirigida ao professor, sua formulação pode fugir do alcance compreensivo do indivíduo comum. A questão, de modo geral, diz respeito ao significado de um termo, expressão, etc. no interior de uma determinada teoria. Este seria o caso de uma pergunta como:

\section{"O que é sinal diacrítico e o que tem a ver com acentuação gráfica?".}

Indo um pouco além, considere-se o ambiente universitário, e, nele, um filósofo e um semanticista discutindo os conceitos de inclusão de classe: hiperonímia e hiponímia. Eles bem poderiam afirmar:

Filósofo: Todo cavalo é um animal.

Semanticista: Mas nem todo animal é cavalo.

E alguém, um aluno, por exemplo, poderia perguntar: "Por quê??" 
Sem dúvida, se alguém fizesse uma pergunta dessas não estaria interessado em animais, ou, menos ainda, em cavalos.

As situações referidas indicam que a terminologia, ou seja, as palavras usadas em cada caso vão passando da linguagem que a maioria das pessoas entende para uma linguagem não usual, envolvendo a necessidade de refinar o conhecimento linguístico e metalinguístico, requerido. Assim, a metalinguagem a ser utilizada varia, vinculando-se, pois, indissociavelmente, ao contexto enunciativo em que foi produzida a intervenção.

\section{POR QUE O CONTEXTO CULTURAL SE RELACIONA, ESTREITAMENTE, COM METALINGUAGEM?}

A importância do contexto ou ambiente - seja físico, seja sociocultural - é determinante, de vez que a mente dos indivíduos estrutura seu entorno e se estrutura em um mundo compartilhado intersubjetivamente. Daí relacionar-se, sistematicamente, "o estudo da linguagem ao da cultura ambiente", realçando-se a contribuição da cultura para "as conceptualizações linguísticas e para a estruturação do pensamento nas diferentes línguas." (DELBECQUE, 2006, p. 11). O mundo em que se vive é povoado e animado por artefatos, símbolos, convenções e sentidos intersubjetivamente partilhados. Por isso mesmo, o papel do contexto físico e cultural é constitutivo da cognição e não apenas seletivo (SINHA, 2005), sendo o habitat humano estruturado e constituído por práticas socioculturais e por normas de uso, em geral implícitas, requerendo que os sujeitos delas se utilizem, na prática, antes mesmo de entender como funcionam.

Como não é inata nem um comportamento meramente imitativo, mas uma ação social situada, a linguagem desenvolve-se paulatinamente, emergindo das e nas práticas sociais, porque é nesse contexto que a mente humana - possuidora de dupla natureza: biológica e social, sendo ainda interativa e dialógica - tem seu berço. Assim, o contexto físico e cultural é o fundamento desse processo, porque permite que os sujeitos se orientem deiticamente com relação a lugar, tempo e pessoa a partir dele. 
Essas coordenadas são pragmáticas, situacionais, históricas, culturais, e os indivíduos precisam interpretá-las para conviver em sociedade.

Sobre a questão da interpretação/compreensão, Dascal e Weizman (1987) analisaram a influência de dois tipos de informação contextual - a extralinguística e a metalinguística - e postularam princípios orientadores da seleção dos indícios ou pistas contextuais a serem consideradas na interpretação, as quais foram retomadas por Dascal (2006):

a) em primeiro lugar, Dascal (2006) retoma a distinção entre dois tipos de contexto, o conhecimento de mundo (extralinguístico) e o conhecimento de convenções e das estruturas sociais e linguísticas (metalinguístico);

b) cada um deles fornece, segundo ele, tipos de pistas contextuais diferentes, subdividindo-se em três níveis: o específico, o superficial e o de fundo.

Os níveis de especificidade e os dois tipos de pistas mantêm paralelismo entre si e envolvem a exploração dessas pistas, processandose em duas etapas:

a) aproximação inicial com a apreensão de traços captáveis de imediato; e

b) avaliação posterior com a verificação do que foi inicialmente apreendido, processando-se através do cotejo entre dados primeiros e demais conhecimentos, inclusive os de fundo. Dascal (2006) ainda propõe, como já o fizera em 1987, outro paralelismo entre as pistas contextuais, tendo por base os processos de apreciação e avaliação.

O interesse nesses estudos reside na perspectiva teórica por eles ensejada, de vez que seus autores definiram metalinguagem enquanto conhecimento contextual. Assim, ao invés de considerar o real em termos de realidade física, com exclusividade, Dascal e Weizman usaram o conceito de contexto, subdividindo-o em contexto extralinguístico (situação interativa imediata, etc.), e contexto metalinguístico (distintos domínios discursivos). 
Assim, a proposta desses dois autores, na verdade, redimensionou o conceito de metalinguagem, de certa forma propiciando um novo olhar ao trabalho de Morato $(2005 ; 2008)$. Nos dois estudos mencionados, a atividade metalinguística ganhou outra dimensão, enquanto conceito essencial ao entendimento da realidade sociocultural, institucional, interacional, como comentado anteriormente.

Interessa, ainda, formular algumas observações a respeito das representações (imagens, conceitos, ideias, mitos) que as pessoas, em geral, têm a respeito da língua e dos processos comunicativos. Essas representações integram os modos de ver e avaliar dos falantes e constituem entendimentos estruturados, em termos de senso comum, constituindo parâmetros sociais. O modo de julgar as variedades dialetais existentes, a avaliação dos dialetos regionais e sociais e o prestígio de uma variante linguística em detrimento das demais decorrem de julgamento social, grupal, e se impõem, estigmatizando ou prestigiando pessoas e seus grupos sociais de origem. Isso implica reconhecer que a metalinguagem autorregula as formas de expressão e de comunicação de uma língua e influencia, também, em nível social e ideológico, determinando ações, preferências e prioridades das pessoas. Assim, quando se fala em metalinguagem, é necessário ter em mente o contexto sociocultural, em termos bastante amplos (COUPLAND; JAWORSKI, 2004).

Parece, então, sobremaneira importante discutir o contexto enunciativo, situacional, cultural, deflagrador da operação metalinguística e, também, destacar a sua condição de conhecimento contextual imprescindível ao entendimento e à produção de linguagem. Isso implica dizer que a opacidade de um texto para alguém pode derivar tanto do desconhecimento do contexto interativo específico no qual se encontra, quanto do contexto metalinguístico específico, digamos, por desconhecer o falante ou leitor os ritos sociais, os modos de abordagem e a terminologia específica da área. Há que se aditar que o ouvinte ou leitor pode, ainda, desconhecer a estrutura convencional de um texto produzido para preencher determinado objetivo, porque um texto de anatomia é diferente de um texto ficcional. Uma conversa entre amigos é 
diferente da exposição oral de um trabalho. E, por fim, a falta de conhecimento de um dado domínio discursivo pode inviabilizar o entendimento de um texto, implicando falta de conhecimento de fundo, por desconhecer o leitor/ouvinte quais as regras gerais para a interação nesse tipo de situação (por exemplo, interlocução entre terapeutas e afásicos).

\section{ENTÃO, O QUE PODE SER CONSIDERADO, DE FATO, COMO UMA OPERAÇÃO METALINGUÍSTICA?}

De acordo com Morato (2008, p. 59), em primeiro lugar faz-se necessário reconsiderar o conceito de competência. Sua recomendação parte exatamente do que pode ou não ser considerado como metalinguagem, conceito legado por Jakobson, em termos de função metalinguística. Tanto o conceito de metalinguagem que o circunscrevia à linguagem verbal quanto o conceito de competência chomskiano são criticados pela autora. Em seu estudo de 2008, a autora remete, em nota de rodapé, a um texto publicado anteriormente (MORATO, 2005, p. 259), no qual afirmara que "a afasia tem sido definida tradicionalmente como um problema metalinguístico (nos termos de Jakobson)". A autora contesta essa visão, por considerá-la reducionista. Segundo ela, a aceitação pura e simples desse ponto de vista leva a crer que os problemas e o tratamento da afasia se limitam de forma exclusiva ao conhecimento metalinguístico do mundo.

Em sua ótica, a perspectiva é inadequada por circunscrever a linguagem ao sistema da língua, eliminando as possibilidades comunicativas não baseadas na linguagem verbal. $O$ conceito de linguagem preconizado pela autora ultrapassa os limites da atividade vocal e, por isso, envolve tanto o que se entende por linguagem quanto o conceito de metalinguagem, tal como postulado por Jakobson. Morato propõe integrar linguagem verbal e não verbal e o faz com base em suas pesquisas com afásicos.

Maingueneau (1997), por sua vez, não vê sentido algum em analisar a relação interativa dissociando emissão/recepção, tratando-as 
como dois comportamentos sequenciais, sem vínculo direto. Em vez disso, o autor considera emissão/recepção como atos simultâneos e inter-relacionados. Essa posição é interessante, porque problematiza a concepção de emissão como um processo que interage com outro processo, o de recepção. Seu ponto de partida é a admissão de que esses dois processos são simultâneos, abandonando de vez a perspectiva sequencial, que se funda no par estímulo/resposta. Assumir tal posição possibilita vislumbrar, pois, a coocorrência e a indissociabilidade dos processos de emissão/recepção comunicacional.

Além do mais, o autor não restringe seu interesse apenas ao material verbal. Em prosseguimento, Maingueneau (1997, p. 59) afirma que "a possibilidade de registrar simultaneamente o som e a imagem permitiu pôr em evidência o caráter multicanal da comunicação [...], que ultrapassa largamente o estrito domínio da língua natural [...]”. O autor destaca que não há dúvida de que as pessoas comunicam-se através de suas emissões vocais, mas elas também se comunicam por meio de silêncios, mímicas, posturas corporais, modos de olhar, maneira de reagir, formas de tratamento polido ou não e uma porção de procedimentos que integram a atividade comunicativa. Segundo ele, a interpretação não está incluída nos enunciados, pois a relação entre enunciado/enunciação não é fixa nem estável, mas uma construção que resulta do trabalho conjunto dos participantes da atividade interativa, num dado contexto de uso da linguagem.

Retomando Morato (2010), a autora insiste que a falta de palavras, ou seja, o não conseguir lembrar-se do nome de algo não implica que o indivíduo seja incapaz de exercitar qualquer atividade metalinguística, ou que não possa refletir sobre o que quer dizer. Em sua argumentação, Morato declara que seus estudos comprovam que as alterações metalinguísticas comuns na afasia, em si e por si mesmas, não chegam a destruir toda a capacidade pragmático-enunciativa, ou as ações reflexivas dos sujeitos sobre a língua e seu funcionamento. Sua perspectiva de investigação considera outros sistemas semiológicos como o gestual e o procedimental, recusando-se ela a admitir que todo tipo de ação reflexiva sobre a linguagem e seu funcionamento possa se restringir ao conhecimento da estrutura linguística, ou das noções de língua detidas pelo falante. 
Para concluir, adita-se que a autora modificou o conceito de metalinguagem, ao considerar como evidências de atividades metalinguísticas certos aspectos comunicativos extralinguísticos como o gesto, o olhar, a postura, a execução de ações direcionadas a um objetivo, que podem operar tanto de modo complementar quanto substitutivo. Ao fazê-lo, Morato uniu o verbal e o não verbal, construindo uma perspectiva analítica diferente daquilo que se entendia por metalinguagem, posicionando-se de modo desfavorável à demarcação de fronteiras entre o verbal e o não verbal, inaugurando o que se poderia chamar de monitoramento metacomunicacional.

\section{PALAVRAS FINAIS}

Este trabalho destacou a relevância teórica do estudo interdisciplinar da mente, discutindo a linguagem enquanto questão sociocultural, cerebral, corpórea e cognitiva, buscando-se explicitar o que se considera essencial a investigações dessa natureza. Apresentou-se o contexto de uso da linguagem como lócus privilegiado para acompanhar e analisar a atividade psíquica em seu todo linguístico-cognitivo-cultural, buscando esclarecer o que sejam os processos epilinguísticos e metalinguísticos e seu vínculo com a metalinguagem, enfatizando-se o papel desta última, enquanto propriedade autorreguladora de linguagem/cognição.

Assim, se a linguagem alia-se à cognição através dos processos epilinguísticos e metalinguísticos, tendo importância decisiva tanto na aquisição das diferentes línguas particulares quanto na reconstrução da linguagem pelos afásicos, é preciso redefinir suas relações com a cognição e as implicações teóricas decorrentes disso. Vale investir na ampliação do conceito de metalinguagem, não limitando seu escopo apenas ao verbal, por exemplo, pois isso implicaria não reconhecer como linguagem o gesto de apontar para um objeto (dêixis), excluindo da análise gestos, mímicas, olhares, posição e movimentos do corpo. A inclusão da linguagem não verbal na análise indica ser possível que o estudo da relação linguagem/cognição possa ser tratado como um todo interdependente. 
Por outro lado, ao se considerar o contexto situacional, fica claro que aquilo que se altera no modo de proceder do indivíduo, tanto na aquisição da linguagem pela criança quanto na sua reconstrução pelos afásicos, processa-se em função da participação do sujeito numa dada prática social, envolvendo linguagem verbal e não verbal, o que mostra, então, que a mudança não se origina exclusivamente nem do exterior nem do interior do indivíduo, mas de ambos, emergindo da necessidade e do desejo de ser parte, de integrar-se.

Estudos interdisciplinares da mente, que inter-relacionem pesquisas provenientes de áreas diversas - para além de seus lugares de institucionalização, que repensem, talvez, o conceito de pensamento antinômico, que complementem estudos de natureza diversa e adotem uma concepção de cognição/linguagem/contexto cultural/(corpo)cérebro mais integrada -, parecem constituir um modo possível de fazer avançar as pesquisas na área das ciências cognitivas.

\section{REFERÊNCIAS}

CANGUILHEM, G. O normal e o patológico. Trad. de Maria Thereza Barrocas. 4 ed. Rio de Janeiro: Forense Universitária, 1995.

COUDRY, M. I. H. Diário de Narciso: discurso e afasia. São Paulo: Martins Fontes, 1988.

COUPLAND, N.; JAWORSKI, A. Sociolinguistic perspectives on metalanguage: reflexivity, evaluation and ideology. In: JAWORSKI, A.; COUPLAND, N.; GALASINSKI, D. (Eds.). Metalanguage: social and ideological perspectives. Berlin: Mouton de Gruyter, 2004.

DASCAL, M.; WEIZMAN, E. Contextual exploitation of interpretation clues in text understanding: an integrated model. In: VERSCHUEREN, J.;

BERTUCCELLI-PAPI, M. (Orgs.). The pragmatic perspective. Amsterdam: John Benjamins, 1987.

DASCAL, M. Interpretação e compreensão. São Leopoldo: Editora UNISINOS, 2006.

DELBECQUE, N. A Linguística cognitiva - compreender como funciona a linguagem. Trad. de Fernanda Oliveira. Lisboa: Instituto Piaget, 2008.

DE LEMOS, C. T. Sobre a aquisição da linguagem e seu dilema (pecado original). Boletim ABRALIN, v. 3, 1982. 
Os processos metafóricos e metonímicos como mecanismos de mudança. Substratum: temas fundamentais em Psicologia e Educação, v. 1, n.3. Trad. de Ernani Rosa. Porto Alegre: Artes Médicas, 1998.

DUPUY, J-P. Nas origens das ciências cognitivas. São Paulo: Ed. da UNESP, 1996.

FAUCONNIER, G. Mental spaces. Cambridge, Mass.: MIT Press, 1994.

FAUCONNIER, G.; TURNER, M. The way we think. New York: Basic Books, 2002.

FOLEY, W. Anthropological linguistics: an introduction. Malden, MA.: Blackwell, 1997.

FREITAS, M.F.Q. Prácticas en comunidad y Psicología Comunitária. In: MONTERO, M. (Coord.) Psicologia Social comunitária - Teoria, método e experiencia. México: Guadalajara, 1994.

GOMBERT, J. E. Metalinguistic development. London: HarvesterWheatshef, 1992.

JAKOBSON, R. Essais de linguistique générale. Paris: Éditions Minuit, 1963.

Relações entre a ciência da linguagem e as outras ciências. V. III Trad. de Maria Bacelar Nascimento. Lisboa: Livraria Bertrand; São Paulo: Martins Fontes, 1974.

KARMILOFF-SMITH, A. A functional approach to child language. Cambridge, UK: Cambridge University Press, 1979.

. A note on the concept of "metaprocedural processes" in linguistic and non-linguistic development. Archives de Psychologie, v. 51, p. 35-40, 1983.

. From metaprocesses to conscious access: evidence from metalinguistic and repair data. Cognition, v. 23, p. 95-147, 1986.

KOLINSKY, R. L'émergence des habilités métalinguistiques. Cahiers de Psychologie Cognitive, v. 6, p. 379-404, 1986.

LURIA, A. R. Pensamento e linguagem: as últimas conferências de Luria. Porto Alegre: Artes Médicas, 1986.

MAINGUENEAU, D. Introdução à linguística. Trad. de Luísa Baptista. Lisboa: Gradiva, 1997. 
MARKOVÁ, I. Dialogicidade e representações sociais: as dinâmicas da mente. Trad. de Pedrinho Guareschi e Sandra Jovchelovitch. Petrópolis, RJ: Vozes, 2006.

MIRANDA, N. S.; SALOMÃO, M. M. (Orgs.) Construções do português do Brasil: da gramática ao discurso. Belo Horizonte: Editora da UFMG, 2009.

MORATO, E. Neurolinguística. In: MUSSALIM, F.; BENTES, A. C. (Orgs.). Introdução à Linguística: domínios e fronteiras. V. 2. São Paulo: Cortez, 2001.

. O interacionismo no campo linguístico. In: MUSSALIM, F.; BENTES, A.C. (Orgs.) Introdução à linguística: domínios e fronteiras. V. 3. São Paulo: Cortez, 2004.

MORATO, E. et al. Análise da competência pragmático-discursiva de sujeitos afásicos que frequentam o Centro de Convivência de Afásicos (CCA- IEL/ UNICAMP). Relatório Final de Pesquisa, FAPESP, Processo 03/02604-9. Campinas, 2005.

O caráter sócio-cognitivo da metaforicidade: o tratamento de expressões formulaicas por pessoas com afasia e doença de Alzheimer. Disponível em:

<http://www.gtlingcog.ufff/lingcog2007/resumos/car_soc_cog_metaf.doc> Acesso em: 9 set. 2008.

. Da noção de competência no campo da linguística. In: I. SIGNORINI (Org.). Situar a língua[gem]. São Paulo: Parábola, 2008. Cortez, 2010.

(Org.). A semiologia das afasias: perspectivas linguísticas. São Paulo:

PIAGET, J. La prise de conscience. Paris: PUF, 1974.

The equilibration of cognitive structures. Chicago: University of Chicago Press, 1985.

REY-DEBOVE, J. Le métalangage: étude du discours sur le langage. Paris: Armand Colin, 1978.

SINHA, C. Blending out of the background: play, props and staging in the material world. Journal of Pragmatics, n. 37, p. 1537-1554, 2005.

TEIXEIRA, J. F. de. Filosofia e ciência cognitiva. Petrópolis, RJ: Vozes, 2004.

TOMASELLO, M. Origens culturais da aquisição do conhecimento humano. Trad. de C. Berliner. São Paulo: Martins Fontes, [1999] 2003. 
Recebido em 26/01/11. Aprovado em 29/02/12.

Title: From the relationship between language and thought to the interdisciplinary study of the mind Authors: Onici Claro Flôres; Rosângela Gabriel

Abstract: This essay discusses the relationship between thought and language, a long lasting theoretical problem, revised now with more emphasis, adding other elements to the considered relationship: a) the cultural context - as an essential factor not as a mere background, and b) the brain studies. A theoretical review of the concepts of metalanguage and metalinguistic activity was conducted, relating them to the studies of aphasia. It is argued that this cyclical reanalysis is due to the contribution of methodological and theoretical findings. At the present time the renewal has derived from a new way of considering the relationship of culture and life experiences in a social group upon individuals cognition, at the light of the results of several studies about brain changing according to experience, which were impossible in the past due to lack of proper methods and techniques. The theme is not trivial, having been stressed by disciplinary divisions. The discussion main point concerns to the biological basis of a possible difference, at the beginning of the process of knowledge construction. This discussion is of immediate interest and, being considered or not, the relationship: cognition/language/cultural context/brain (body) is crucial to Cognitive Sciences.

Keywords: Cognition. Language. Metalanguage. Metalinguistic activity. Aphasia.

Título: De la relación pensamiento y lenguaje al estúdio interdisciplinar de la mente

Autores: Onici Claro Flôres; Rosângela Gabriel

Resumen:: En este ensayo, se retoma la discusión sobre la relación pensamiento y lenguaje, ampliándose el alcance del abordaje, y se reemplaza el término pensamiento por cognición; se agregan al debate el contexto cultural, como factor esencial, y no apenas como telón de fondo, y los estudios del cerebro, como sustentación de algunas hipótesis teóricas actualmente vehiculadas. Además, son introducidos los conceptos de metalenguaje $y$ de actividad metalingüistica, relacionándolos a la investigación sobre afasia. Se argumenta sobre la importancia de la cultura y de la vida en sociedad para la cognición, además de daser destaque a los estudios del cerebro, históricamente rechazados por motivos religiosos o éticos. En pauta están las bases biológicas y, posiblemente, también culturales de una posible diferencia en el estado inicial del proceso de construcción del conocimiento, cuya discusión continúa, en la actualidad, enfocando cognición/lenguaje/contexto cultural/cerebro (cuerpo) como una relación esencial a las investigaciones en el área de las Ciencias Cognitivas.

Palabras-clave: Cognición. Lenguaje. Metalenguaje. Actividad metalingüistica. Afasia. 